\title{
The prevalence of BRCAI mutations among young women with triple-negative breast cancer
} SR Young ${ }^{1}$, Robert T Pilarski2 ${ }^{2}$ Talia Donenberg ${ }^{3}$, Charles Shapiro ${ }^{4}$ Lyn S Hammond ${ }^{5}$, Judith Miller ${ }^{6}$, Karen A Brooks ${ }^{1}$, Stephanie Cohen ${ }^{7}$, Beverly Tenenholz ${ }^{8}$, Damini DeSai ${ }^{9}$, Inuk Zandvakili ${ }^{10}$, Robert Royer ${ }^{10}$, Song $\mathrm{Li}^{10}$ and Steven A Narod*10

\author{
Address: ${ }^{1}$ Department of Obstetrics and Gynecology, University of South Carolina School of Medicine, USA, ${ }^{2}$ Department of Internal Medicine \\ Clinical Cancer Genetics Program, Ohio State University, Columbus, OH, USA, ${ }^{3}$ Department of Obstetrics \& GynecologyUniversity of Miami/ \\ Jackson Health System, Miami, Florida, USA, ${ }^{4}$ Department of Internal Medicine, Division of Hematology and Oncology, Ohio State University, \\ USA, ${ }^{5}$ Division of Genetics, Medical University of South Carolina, Charleston, SC, USA, ${ }^{6}$ Carle Clinic Medical Genetics, University of Illinois \\ College of Medicine, Urbana, IL, USA, ${ }^{7}$ Medical Genetics, St. Vincent Hospital, Indianapolis, IN, USA, ${ }^{8}$ Geisinger Medical Center, Danville, PA, \\ USA, ${ }^{9}$ Joe Arrington Cancer Center, Lubbock, TX, USA and ${ }^{10}$ Women's College Research Institute, Department of Public Health, The University of \\ Toronto, Toronto, Canada \\ Email: SR Young - sryoung37@aol.com; Robert T Pilarski - robert.pilarski@osumc.edu; Talia Donenberg - tdonenberg@med.miami.edu; \\ Charles Shapiro - charles.shapiro@osumc.edu; Lyn S Hammond - hammondl@musc.edu; Judith Miller - Miller12@uiuc.edu; \\ Karen A Brooks - Kabrooks@richmed.medpark.sc.edu; Stephanie Cohen - sacohen@stvincent.org; \\ Beverly Tenenholz - btenenholz@geisinger.edu; Damini DeSai - ddesai@covhs.org; Inuk Zandvakili - inukzand@gmail.com; \\ Robert Royer - robert.royer@wchospital.ca; Song Li - song.li@wchospital.ca; Steven A Narod* - steven.narod@wchospital.ca \\ * Corresponding author
}

Published: 19 March 2009

BMC Cancer 2009, 9:86 doi:10.1/86/147/-2407-9-86
Received: II June 2008

Accepted: 19 March 2009

This article is available from: http://www.biomedcentral.com/I47I-2407/9/86

(c) 2009 Young et al; licensee BioMed Central Ltd.

This is an Open Access article distributed under the terms of the Creative Commons Attribution License (http://creativecommons.org/licenses/by/2.0), which permits unrestricted use, distribution, and reproduction in any medium, provided the original work is properly cited.

\begin{abstract}
Background: Molecular screening for BRCAI and BRCA2 mutations is now an established component of risk evaluation and management of familial breast cancer. Features of hereditary breast cancer include an early age-ofonset and over-representation of the 'triple-negative' phenotype (negative for estrogen-receptor, progesteronereceptor and HER2). The decision to offer genetic testing to a breast cancer patient is usually based on her family history, but in the absence of a family history of cancer, some women may qualify for testing based on the age-ofonset and/or the pathologic features of the breast cancer.

Methods: We studied 54 women who were diagnosed with high-grade, triple-negative invasive breast cancer at or before age 40. These women were selected for study because they had little or no family history of breast or ovarian cancer and they did not qualify for genetic testing using conventional family history criteria. BRCAI screening was performed using a combination of fluorescent multiplexed-PCR analysis, BRCAI exon- $136 \mathrm{~kb}$ duplication screening, the protein truncation test (PTT) and fluorescent multiplexed denaturing gradient gel electrophoresis (DGGE). All coding exons of BRCAI were screened. The two large exons of BRCA2 were also screened using PTT. All mutations were confirmed with direct sequencing.
\end{abstract}

Results: Five deleterious BRCAI mutations and one deleterious BRCA2 mutation were identified in the 54 patients with early-onset, triple-negative breast cancer (1 I\%).

Conclusion: Women with early-onset triple-negative breast cancer are candidates for genetic testing for BRCAI, even in the absence of a family history of breast or ovarian cancer. 


\section{Background}

The two major contributors to hereditary breast cancer are the cancer susceptibility genes BRCA1 and BRCA2 [1]. Genetic testing for BRCA1 and BRCA2 mutations has been established throughout North America and much of Europe. Not all women are candidates for testing - in general, testing is offered to a woman who has a probability of ten percent or greater for being positive for a mutation. An exception is made for women from particular ethnic backgrounds, such as Ashkenazi Jewish, French-Canadian or Polish women; in these groups, a small number of founder mutations is responsible for the majority of hereditary cancers [2-4]. For women in these groups, testing is inexpensive and eligibility criteria can be relaxed. However, in a mixed ethnic population, such as is found in most of the United States and Canada, testing involves the complete screening of the coding sequences of the two genes. In order to maximize both the efficiency of testing and the public health impact of a genetic screening program, many centers offer screening to women when the prior probability of finding a mutation is ten percent or greater. Several mathematical models such as BRCAPRO and BOADICEA can be used to estimate the prior probability of having a mutation $[5,6]$. These models consider age-of-onset and family history of cancer. Certain characteristics of the breast cancer can also be used to help predict the presence of a mutation. BRCA1-associated cancers are typically high-grade and are 'triple negative'; i.e. are negative for estrogen-receptor (ER), progesterone-receptor (PR) and HER2 expression [7,8]. The majority of triplenegative cancers exhibit the basal phenotype, i.e., they also express basal type cytokeratins (keratin 5 or keratin 6) or epidermal growth factor receptor (EGFR) (80\% to $90 \%$ of triple-negative cancers are basal phenotype). The proportion of BRCA1-associated cancers that are of the 'basal phenotype' has been estimated to be $88 \%$ by Foulkes et al [7] and 57\% by Lakhani et al. [8]. Furthermore, the proportion of BRCA1-associated cancers that are ER-negative (one of the component features) diminishes with increasing age-of-onset. Foulkes et al found that $81 \%$ of BRCA1associated breast cancers diagnosed before age 45 were ER-negative, compared to $62 \%$ of cancers in women diagnosed after age 65 [9]. In contrast to the high proportion among BRCA1-associated breast cancer, only about 15\% of all women with breast cancer have triple-negative cancers [10]. Therefore, this subgroup of women is expected to be enriched for BRCA1-mutation carriers. In this study, we estimate the proportion of BRCA1 mutation carriers among women diagnosed at age 40 or younger with triple-negative breast cancer, without a significant family history of cancer.

\section{Methods}

Cases for study were identified from two hospital systems (the Palmetto Health Richland/Baptist Hospitals, Colum- bia SC and the Cancer Genetics Clinic of Ohio State University, Columbus) and through genetic counselors affiliated with the National Society of Genetic Counselors Cancer Special Interest Group. Women diagnosed with breast cancer at age 40 years and younger and who did not have a significant family history of breast or ovarian cancer were chosen for study. We also excluded patients of Ashkenazi Jewish heritage because they would be eligible for routine genetic testing (founder mutations) in any cancer center and because we do not expect to find nonfounder mutations in this population. A total of 97 patients were submitted for evaluation, of which 58 were eligible for the study. Women were excluded if there was insufficient documentation of triple-negative status to include them in the study $(n=32)$ or if they had a positive family history of cancer $(n=6)$ or if the age of diagnosis was missing $(n=1)$. Twenty-eight patients were submitted from the Palmetto Health Richland and Baptist Hospitals. Women were identified though the Palmetto Health Cancer Directory or at presentation to a weekly breast cancer conference. A woman was eligible if her medical records indicated that her breast carcinoma was grade III and was negative for ER, PR and HER2. HER2 overexpression was defined as moderate to strong staining that totally encircles the cell membrane $(2+$ or $3+)$. Women with a cancer diagnosis within three years of study initiation were invited to participate. These 14 women were mostly from South Carolina. Nineteen patients were submitted from Ohio State University: these women were identified from a database of 1300 breast cancer patients who had been accrued to a separate research protocol. They were diagnosed with breast cancer at one of three hospitals in the Columbus, $\mathrm{OH}$ area, between May 2003 and August 2006. Informative cases were chosen for being high-grade, triple-negative breast cancers diagnosed at age 40 and younger. Twenty-five patients were recruited through the National Society of Genetic Counselors Cancer Special Interest Group. An email notification was posted on the society list-serve (NSGC Cancer-SIG). This list-serve is read by approximately 300 genetic counselors who specialize in cancer. The notice solicited breast cancer patients who diagnosed at age 40 or younger, had no cancer family history and who were 'triple-negative'. Twentytwo counselors submitted patients. All patients accrued through the NSGC Cancer-SIG were interviewed by a genetic counselor and a three-generation pedigree was drawn. The study was approved by the institutional review board (IRB) of the Palmetto Health Richland/Baptist Hospitals IRB (Columbia, SC 29201) and of the Women's College Research Institute.

\section{Laboratory methods}

DNA was extracted from whole blood lymphocytes using standard methodology. We evaluated the entire coding sequence of BRCA1 and the large exons 10 and 11 of 
BRCA2 for mutations. DNA was screened for two common BRCA1 alterations (185delAG and 5382insC) and one BRCA2 alteration (6174delT) by rapid fluorescent multiplexed-PCR analysis, FMPA [11]. All patients were screened for the BRCA1 exon-13 $6 \mathrm{~kb}$ duplication [12]. BRCA1 exon 11, and BRCA2 exons 10 and 11 were screened using protein truncation test, PTT (TNT ${ }^{\mathrm{TM}}$ rabbit reticulocyte lysate system, Promega, and [35S]methionine/cysteine, New England Nuclear). All other BRCA1 exons, with the exception of exons $1 \mathrm{a} / \mathrm{b}$ and 4 , were also scanned by fluorescent multiplexed denaturing gradient gel electrophoresis, DGGE [13]. The first $2 \mathrm{~kb}$ at the beginning and the end of exon 11 were also included in the DGGE analysis, as were all exon-intron boundaries. All variants identified by either PTT or DGGE were confirmed by direct sequencing. These methods are expected to identify almost all BRCA1 mutations and 70\% of BRCA2 mutations which are identifiable through direct sequencing.

\section{Results}

A total of 58 women with triple-negative cancer was eligible for testing, but four samples were of poor quality and these patients were excluded, leaving 54 patients. The mean age of cancer diagnosis was 34.7 years (range 24 to 40 years). None of the patients had a significant family history as defined by the American Society of Clinical Oncology [14]. No patient had a past history of ovarian cancer and no patient had a first-degree relative with ovarian cancer or breast cancer. No patient had a family history of male breast cancer. Two patients had bilateral breast cancer; in both instances the triple-negative tumour was the first tumour to be diagnosed and neither had a family history of breast or ovarian cancer.

Six deleterious mutations were identified in the 54 patients (11\%); five in BRCA1 and one in BRCA2 (table $1)$. The 5382insC mutation was seen on two occasions and the four other mutations were seen one time each. All mutations were protein-truncating. A BRCA1 mutation was identified in 5 of 34 white patients (15\%) and none of 20 patients of other ethnicities (ten African-American, six Hispanic, two Asian, two mixed). The single BRCA2 mutation was found in an African-American woman (4936delAG). A mutation was found in 0 of 11 women diagnosed with breast cancer at or before age 30 and in 6 of 43 women (14\%) diagnosed between ages 31 and 40 . Nine additional BRCA1 variants of no, or unknown, clinical significance were also identified (table 2).

\section{Discussion}

These data support the position that early-onset triplenegative breast cancer is an indicator that can be used to help to identify candidates for BRCA1 mutation testing. Our study is relatively small (54 patients) but we confirm similar observations made by others. To date, no single study has been large or definitive, and therefore it is important to consider the results of all studies in aggregate. Lidereau et al found that 6 of 70 women (9\%) with breast cancer diagnosed at age 35 or below, unselected for family history, carried a BRCA1 mutation [15]. However, the proportion with mutations was 29\% (4 of 14) for those with ER-negative, high-grade tumours, compared to only 4\% (2 of 56) among women with other tumour types (odds ratio $=11 ; \mathrm{p}=0.007$ ). Among women in our study who were diagnosed before the age of 35 , the mutation prevalence was $8.3 \%$. In a study of 254 white women from the UK, diagnosed with breast cancer before age 36, a germline BRCA1 or BRCA2 mutation was identified in only $6 \%$ (ref 16 ). Of the 15 women with germline mutations, only one had a family history of breast or ovarian cancer. In this early study, the study sample was not subdivided by ER-status or other factors.

A number of studies suggest that breast cancers associated with BRCA1 mutations are likely to be triple-negative and the majority of these are also the basal phenotype $[7,8,17$ 19]. Basal-like tumours express certain cytokeratins characteristic of the 'basal' layer myoepithelial cells lining the terminal duct lobular unit (namely cytokeratins 5, 6, 14 and 17) [20]. Basal-like tumours are usually high-grade, exhibit comedeonecrosis, pushing borders and an inflammatory lymphocytic infiltrate.

Other studies included women who were selected for family history or ethnic group. Chang et al. studied women with familial breast cancer (at least one first-degree relative with either breast or ovarian cancer) diagnosed before age 45 [17]. They found that 6 of 24 (25\%) patients with an ER-negative, high-grade tumour had a germline BRCA1

Table I: Deleterious mutations identified among fifty-four triple-negative cases:

\begin{tabular}{llllll}
\hline Gene & Exon & Mutation & Mutation Type & Age of Onset \\
\hline BRCAI & II & I294del40 & Deletion & 35 & Caucasian \\
BRCAI & II & 2800delA & Deletion & 32 & Irish/Scottish \\
BRCAI & 15 & 473 IC>T & Nonsense & 36 & 38 \\
BRCAI & 20 & 5382 insC & Insertion & 39 & Caucasian \\
BRCAI & 20 & 5382 insC & Insertion & 39 & Caucasian \\
BRCA2 & II & 4936 delAG & Deletion & & African American
\end{tabular}


Table 2: Unclassified variants identified among fifty-four triple-negative cases:

\begin{tabular}{lllllll}
\hline Gene & Exon & Mutation & Designation & Mutation Type & Age of Onset & Ethnic Group \\
\hline BRCAI & 22 & $676 \mathrm{C}>\mathrm{A}$ & SI86Y & Missense & 36 & Puerto Rican \\
BRCAI & 16 & $4956 \mathrm{~A}>\mathrm{G}$ & SI6I3G & Missense & 40 & African American \\
BRCAI & 15 & $4654 \mathrm{G}>\mathrm{T}$ & SI5I2I & Missense & 36 & Caucasian \\
BRCAI & 11 & $1186 \mathrm{~A}>\mathrm{G}$ & Q356R & Missense & 40 & Iranian \\
\hline
\end{tabular}

mutation. Haffty et al. that reported that eight of 34 women with triple-negative breast cancer had a BRCA1 mutation (24\%), but these included women with a strong family history of breast cancer [18]. Foulkes et al. found that of $24 \%$ of 72 Ashkenazi Jewish patients diagnosed before age 65 with high grade, ER-negative, HER2-negative breast cancers had a germline BRCA1 mutation [7]. However, the frequency of mutations is known to be high in this group. Given that all Ashkenazi Jewish women with breast cancer are candidates for BRCA mutation testing, we excluded this group from the present study.

Our study has several limitations. Our subjects were derived from various sources, including a populationbased series of cases (Ohio), and from a US hospital (North Carolina) and from women who presented for genetic risk assessment to various clinics across the country. The determination of grade, ER, PR and HER2 status was based on review of pathology report and there was no central pathology review (however, this situation accurately reflects actual clinical practise). The purpose of this study was to estimate the prevalence of BRCA1 mutations and the entire BRCA2 gene was not screened. However, the triple-negative phenotype is not characteristic of BRCA2-associated breast cancers. We expect that the majority of BRCA mutations diagnosed in the triple-negative, family history negative subgroup cancers will be BRCA1. In most situations, genetic counsellors will offer to test for both genes, and if a woman is insured, testing for both genes will be covered. However, for women who do not have full coverage, or in countries where resources are limited, some may wish to test triple-negative patients for BRCA1 only.

All five BRCA1 mutations were seen in white women between the ages of 31 and 40; in this subgroup the mutation prevalence was $17 \%$. It is interesting that no mutation was identified in a woman diagnosed before age 30 ; however this subgroup was small and it is in not clear if this is a chance finding. Further studies will be useful in determining if there are other genetic markers of very early-onset breast cancer.

The criteria used to offer genetic testing to a patient varies from center to center, but in general, testing is usually offered to a woman if the probability of finding a muta- tion exceeds ten percent [14]. Most guidelines for selecting patients rely on family history, but in many centers, genetic testing is routinely offered to all women diagnosed with breast cancer under the age of 40 . In the absence of a family history, fewer than ten percent of patients in this group are expected to carry a BRCA mutation.

\section{Conclusion}

Our study indicates that young women with a high-grade triple-negative cancer and no family history of cancer may be candidates for genetic testing. However, women with other histologic forms of cancer (e.g. ER-positive or HER2positive) and with no family history are unlikely to carry a mutation.

\section{Authors' contributions}

SRY conceived of the study and helped draft manuscript

RTP, TD, CS, LSH, JM, KAB, SC, BT, DD, coordinated the activities at their centers

IZ, RR, SL carried out molecular assays

SAN oversaw the data collection and statistical analysis and helped draft the manuscript.

\section{Acknowledgements}

We would like to acknowledge the cooperation and assistance of members of the National Society of Genetic Counseling Cancer Genetic Special Interest Group throughout the United States who made many of the samples available for study, including Jennifer Burton, Lisa Brown, Michelle Horner, Victoria Vincent, Elizabeth Hoodfar, Linda Cooper, Sharon Solomon, Anne Naumer, Nancy Hanson, Kory Jasperson, Jill Polk, Kerry Crandall, Karen Hanson, Melanie Taylor, Melanie Pierce. We thank pathologist Paul L. Guerry, MD, for his assistance. Samples from The Ohio State University were obtained from the Spielman Breast Cancer Tissue Bank.

\section{References}

I. Narod SA, Foulkes WD: BRCAI and BRCA2: 1994 and beyond. Nature Rev Cancer 2004, 4:665-76.

2. Warner E, Foulkes W, Goodwin P, Meschino W, Blondal J, Paterson C, Ozcelik H, Goss P, Allingham-Hawkins D, Hamel N, Di Prospero L, Contiga V, Serruya C, Klein M, Moslehi R, Honeyford J, Liede A, Glendon G, Brunet JS, Narod S: Prevalence and penetrance of BRCAI and BRCA2 gene mutations in unselected Ashkenazi Jewish women with breast cancer. I Natl Cancer Inst 1999, 91:124I-7.

3. Tonin PN, Mes-Masson AM, Futreal PA, Morgan K, Mahon M, Foulkes WD, Cole DE, Provencher D, Ghadirian P, Narod SA: Founder 
BRCAI and BRCA2 mutations in French Canadian breast and ovarian cancer families. Am J Hum Genet 1998, 63:|34I-5I.

4. Górski B, Byrski T, Huzarski T, Jakubowska A, Menkiszak J, Gronwald J. Pluzañska A, Bebenek M, Fischer-Maliszewska L, Grzybowska E, Narod SA, Lubinski J: Founder mutations in the BRCAI gene in Polish families with breast-ovarian cancer. Am J Hum Genet 2000, 66:1963-8.

5. Euhus DM, Smith KC, Robinson L, Stucky A, Olopade OI, Cummings S, Garber JE, Chittenden A, Mills GB, Rieger P, Esserman L, Crawford B, Hughes KS, Roche CA, Ganz PA, Seldon J, Fabian CJ, Klemp J, Tomlinson G: Pretest prediction of BRCAI or BRCA2 mutation by risk counselors and the computer model BRCAPRO. I Nat Cancer Inst 2002, 94:844-5I.

6. Antoniou AC, Pharoah PP, Smith P, Easton DF: The BOADICEA model of genetic susceptibility to breast and ovarian cancer. Brit J Cancer 2004, 9 I: I 1580-1590.

7. Foulkes WD, Stefansson IM, Chappuis PO, Bégin LR, Goffin JR, Wong N, Trudel M, Akslen LA: Germline BRCAI mutations and a basal epithelial phenotype in breast cancer. J Natl Cancer Inst 2003, 95: | 482-5.

8. Lakhani SR, Reis-Filho JS, Fulford L, Penault-Llorca F, Vijver M van der, Parry S, Bishop T, Benitez J, Rivas C, Bignon YJ, Chang-Claude J, Hamann U, Cornelisse CJ, Devilee P, Beckmann MW, Nestle-Krämling C, Daly PA, Haites N, Varley J, Lalloo F, Evans G, Maugard C, Meijers-Heijboer H, Klijn JG, Olah E, Gusterson BA, Pilotti S, Radice P, Scherneck S, Sobol H, Jacquemier J, Wagner T, Peto J, Stratton MR, McGuffog L, Easton DF, Breast Cancer Linkage Consortium: Prediction of BRCAI status in patients with breast cancer using estrogen receptor and basal phenotype. Clin Cancer Res 2005, I I:5175-80.

9. Foulkes WD, Metcalfe K, Sun P, Hanna WM, Lynch HT, Ghadirian P, Tung N, Olopade OI, Weber BL, McLennan J, Olivotto IA, Bégin LR, Narod SA: Estrogen receptor status in BRCA1- and BRCA2related breast cancer: the influence of age, grade, and histological type. Clin Cancer Res 2004, 10:2029-34.

10. Dent R, Trudeau M, Pritchard KI, Hanna WM, Kahn HK, Sawka CA, Lickley LA, Rawlinson E, Sun P, Narod SA: Triple-negative breast cancer: clinical features and patterns of recurrence. Clin Cancer Re 2207, 13:4429-34.

II. Kuperstein G, Foulkes WD, Ghadirian P, Hakimi J, Narod SA: A rapid fluorescent multiplexed-PCR analysis (FMPA) for founder mutations in the BRCAI and BRCA2 genes. Clin Genet 2000, 57:213-20.

12. The BRCAI Exon I3 Duplication Screening Group: The exon 13 duplication in the BRCAI gene is a founder mutation present in geographically diverse populations. the BRCAI exon 13 duplication screening group. Am J Hum Genet 2000, 67:207-I2.

13. Zhang S, Kuperstein G, Narod SA: Mutation screening using fluorescence multiplex denaturing gradient gel electrophoresis (FMD): Detecting mutations in the BRCAl gene. Nat Protoc 2006, I:3101-10.

14. ASCO: Statement of the American Society of Clinical Oncology: Genetic Testing for Cancer Susceptibility. J Clin Oncol 1996, 14:1730-6.

15. Lidereau R, Eisinger $F$, Champème $M H$, Noguès $C$, Bièche I, Birnbaum $D$, Pallud $C$, Jacquemier J, Sobol H: Major improvement in the efficacy of BRCAI mutation screening using morphoclinical features of breast cancer. Cancer Res 2000, 60:1206-10.

16. Peto J, Collins N, Barfoot R, Seal S, Warren W, Rahman N, Easton DF, Evans C, Deacon J, Stratton MR: Prevalence of BRCAI and BRCA2 gene mutations in patients with early-onset breast cancer. J Natl Cancer Inst 1999, 91 :943-9.

17. Chang J, Hilsenbeck SG, Sng JH, Wong J, Ragu GC: Pathological features and BRCAI mutation screening in premenopausal breast cancer patients. Clin Cancer Res 200I, 7:1739-42.

18. Haffty BG, Yang Q, Reiss M, Kearney T, Higgins SA, Weidhaas J, Harris L, Hait W, Toppmeyer D: Locoregional relapse and distant metastasis in conservatively managed triple negative earlystage breast cancer. J Clin Oncol 2006, 24:5652-7.

19. Farshid G, Balleine RL, Cummings M, Waring P, Kathleen Cuningham Consortium for Research into Familial Breast Cancer (kConFab) Morphology of breast cancer as a means of triage of patients for BRCA I genetic testing. Am J Surg Pathol 2006, 30: I 357-66.
20. Gusterson BA, Ross DT, Heath VJ, Stein T: Basal cytokeratins and their relationship to the cellular origin and functional classification of breast cancer. Breast Cancer Res 2005, 7:143-8.

\section{Pre-publication history}

The pre-publication history for this paper can be accessed here:

http://www.biomedcentral.com/1471-2407/9/86/prepub
Publish with Bio Med Central and every scientist can read your work free of charge

"BioMed Central will be the most significant development for disseminating the results of biomedical research in our lifetime. "

Sir Paul Nurse, Cancer Research UK

Your research papers will be:

- available free of charge to the entire biomedical community

- peer reviewed and published immediately upon acceptance

- cited in PubMed and archived on PubMed Central

- yours - you keep the copyright
BioMedcentral 